\title{
Thorax: Annual Report October 1992-September 1993
}

This has been a record year for Thorax. Once again there has been a considerable increase in the number of submitted manuscripts-a total of 702 being a new record for the journal (see figure). The number of surgical papers submitted remains fairly steady at about 35 .

Table 1 shows the divisions of articles submitted during the year compared with the previous year. There has been a steady growth, particularly in original manuscripts, as well as in short reports. The journal has developed a policy of two or three editorials in each issue, concentrating on directed editorials, and this is reflected in the high number of editorials published in the current year.

Table 2 summarises the decision times for submitted papers. The time for the first decision on original papers has risen while that for short reports has remained constant. The longer decision time compared with last year is in part because papers that were out for review at the end of last year were not included in last year's report, but it also reflects a somewhat slower turnover. This also reflects the increased volume of work being handled. Efforts will be made again during the coming year to reduce the time from receipt of an article to the first decision. The longer time taken for a final decision of a paper resubmitted (31 days mean) again reflects the increased volume of work going through the journal offices. The Associate Editors are now becoming increasingly involved in reviewing and revising resubmitted manuscripts which last year had been carried out almost entirely by the Editor. The number of papers submitted to the journal means that the Associate Editors are having to become more involved in reviewing resubmitted articles.

Thorax has responded to the increased demand from authors by increasing its pagination by $10 \%$ during the year. Our rate of acceptance for original papers stands at $45 \%$ and $27 \%$ for short reports, which is a similar rate to last year. We are also com-

Table 1 Articles received 1991-2 and 1992-3

\begin{tabular}{lcc}
\hline & $1991-2$ & $1992-3$ \\
\hline Original papers & 372 & 415 \\
Short reports & 206 & 219 \\
Review series & 16 & 24 \\
Editorials & 27 & 44 \\
Total & 621 & 702 \\
\hline
\end{tabular}

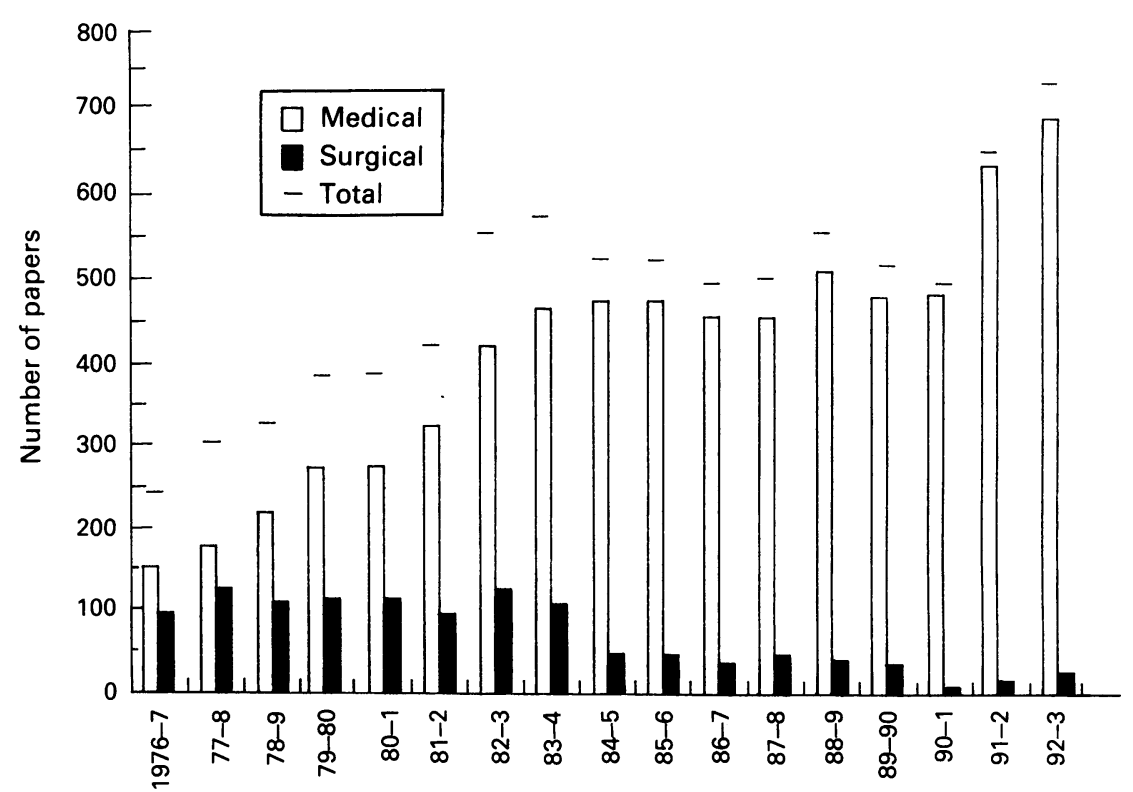

Annual total submission of manuscripts

mitted to minimising the time from acceptance of an article to publication. Currently this is running at $3-4$ months, which is the shortest possible time that can be achieved by the Technical Editor.

For 1994 we are introducing short papers in addition to case reports (which used to be called short reports). These will occupy no more than two pages of the journal $(1400$ words) and should encourage scientists to submit to us preliminary observations or "hot topics" on subjects that

Table 2 Decision times for submitted papers, 1992-3

\begin{tabular}{lcc}
\hline & $\begin{array}{l}\text { Original } \\
\text { papers }\end{array}$ & $\begin{array}{l}\text { Short } \\
\text { reports }\end{array}$ \\
\hline Number & 371 & 176 \\
Time to first decision (days) & & \\
$\quad$ Mean & 87 & 55 \\
$\quad$ Median & 79 & 50 \\
First quartile (days) & 58 & 38 \\
Papers resubmitted (n) & 138 & 44 \\
Time to final decision (days) & & \\
$\quad$ Mean & 31 & 25 \\
$\quad$ Median & 18 & 12 \\
\hline
\end{tabular}

would merit a preliminary report. The short report format will now remain only for case reports and will, as at present, comprise a maximum of 850 words. There is currently a delay of about 10 months from acceptance of case reports to publication.

In 1994 we will be publishing a series of editorials on paediatric respiratory medicine as part of our commitment to encouraging paediatricians with an interest in respiratory medicine to submit original articles to Thorax in order to consolidate our commitment to paediatric respiratory disease.

We will continue to encourage our reviewers to return manuscripts within 21 days. The standard of reviewing for Thorax has increased enormously over the last few years and once again the Associate Editors and the Editor are indebted to all reviewers for the considerable amount of work they have put in to improve the quality of the journal.

Thorax appears in very good shape and we hope that its standard and the increasing rate of submission of original articles will improve further during 1993-4.

A list of reviewers approached during the last year appears on the following page-we are very grateful indeed to all these people. 
Reviewers used from 1 October 1992 to 30 September 1993

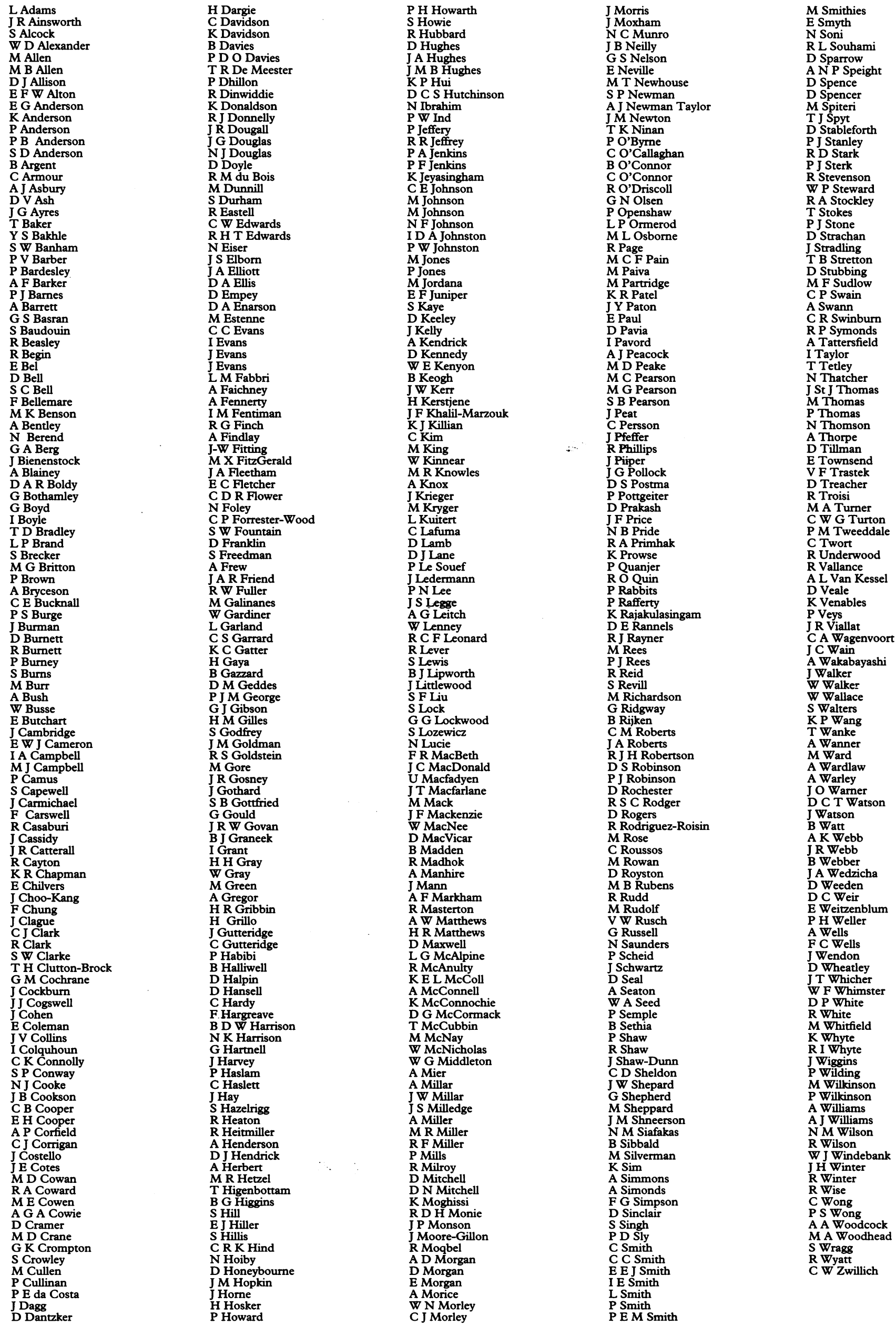

